\title{
Continuous, but not Intermittent, Antipsychotic Drug Delivery Intensifies the Pursuit of Reward Cues
}

\author{
Anne-Marie Bédard', Jérôme Maheux ${ }^{2}$, Daniel Lévesque ${ }^{2}$ and Anne-Noël Samaha*,1,3 \\ 'Department of Pharmacology, Faculty of Medicine, Université de Montréal, Montreal, QC, Canada; ${ }^{2}$ Faculty of Pharmacy, Université de \\ Montréal, Montreal, QC, Canada; ${ }^{3}$ CNS Research Group, Faculty of Medicine, Université de Montréal, Montreal, QC, Canada
}

\begin{abstract}
Chronic exposure to antipsychotic medications can persistently change brain dopamine systems. Most studies on the functional significance of these neural changes have focused on motor behavior and few have addressed how long-term antipsychotic treatment might influence dopamine-mediated reward function. We asked, therefore, whether a clinically relevant antipsychotic treatment regimen would alter the incentive motivational properties of a reward cue. We assessed the ability of a Pavlovian-conditioned stimulus to function as a conditioned reward, as well as to elicit approach behavior in rats treated with haloperidol, either continuously (achieved via subcutaneous osmotic minipump) or intermittently (achieved via daily subcutaneous injections). Continuous, but not intermittent, treatment enhanced the ability of amphetamine to potentiate the conditioned reinforcing effects of a cue associated with water. This effect was not related to differences in the ability to attribute predictive value to a conditioned stimulus (as measured by conditioned approach behavior), but was potentially linked to the development of behavioral supersensitivity to amphetamine and to augmented amphetamine-induced immediate early-gene expression (c-fos and Nur77) in dorsal striatopallidal and striatonigral cells. By enhancing the ability of reward cues to control behavior and by intensifying dopamine-mediated striatopallidal and striatonigral cell activity, standard (ie, continuous) antipsychotic treatment regimens might exacerbate drug-seeking and drug-taking behavior in schizophrenia. Achieving regular but transiently high antipsychotic levels in the brain (as modeled in the intermittent condition) might be a viable option to prevent these changes. This possibility should be explored in the clinic.

Neuropsychopharmacology (201 I) 36, 1248-1259; doi:I0.1038/npp.20 II.10; published online I6 February 201 I
\end{abstract}

Keywords: antipsychotics; treatment mode; conditioned reward; dopamine; supersensitivity; immediate early gene

\section{INTRODUCTION}

Nearly one in two individuals with schizophrenia symptoms have a history of drug abuse or addiction (Kavanagh et al, 2002; Regier et al, 1990). Two principal hypotheses have been suggested to explain this. First, the vulnerability to psychosis and drug abuse might share overlapping neural substrates and could be likely to co-occur in the same individual (Chambers et al, 2001). However, the phenotypic heterogeneity in schizophrenia makes it unlikely that a single neurobiological deficit underlies the illness (Keshavan et al, 2008). Second, drugs might be abused to cope with the illness (Khantzian, 1985) and antipsychotic medication side effects (Schneier and Siris, 1987). However, this idea lacks strong empirical support (Gregg et al, 2007;

*Correspondence: Dr A-N Samaha, Department of Pharmacology, Faculty of Medicine, Université de Montréal, C P 6128, Succursale Centre-ville, Montreal, QC, Canada H3C 317. Tel: + I 514343 61।1; Fax: + | 514343 229|; E-mail: anna.samaha@umontreal.ca Received 26 October 2010; revised 7 January 2011; accepted 7 January 20II
Krystal et al, 2006), and drug use aggravates rather than alleviates schizophrenia symptoms and medication side effects (Pencer and Addington, 2003; Potvin et al, 2006). A third, complementary, but often overlooked hypothesis is that chronic antipsychotic treatment might alter reward function (Kosten et al, 1996; LeDuc and Mittleman, 1995). This possibility is supported by pre-clinical evidence. Thus, although acute exposure to antipsychotics/D2 antagonists generally reduces the incentive motivational properties of primary and conditioned rewards (Beninger et al, 1989; Le Moal and Simon, 1991), chronic antipsychotic treatment can enhance reward function. For example, chronic antipsychotic treatment augments operant responding for intravenous injections of cocaine (Howell and Byrd, 1992; Roberts and Vickers, 1987), facilitates the acquisition of heroin self-administration (Stinus et al, 1989), enhances cocaine-induced psychomotor sensitization (Fukushiro et al, 2008; LeDuc and Mittleman, 1993), and facilitates conditioned place preference to cocaine (Fukushiro et al, 2007; Kosten et al, 1996) and heroin (Stinus et al, 1989).

How might antipsychotic treatment alter reward function? One possibility is by inducing dopamine receptor 
supersensitivity within dopamine pathways. Although all antipsychotics occupy dopamine D2/3 receptors and reduce dopamine neurotransmission acutely, their chronic use can induce dopamine receptor supersensitivity. This is linked to increases in the number and sensitivity of striatal D2 receptors (Ginovart et al, 2009; Samaha et al, 2007, 2008) and an enhanced psychomotor response to dopaminergic drugs (Pudiak and Bozarth, 1997; Rebec et al, 1982; Samaha et al, 2007; Smith and Davis, 1975). In addition to mediating psychomotor behavior, dopamine functions as a 'teaching signal' to enable the association of neutral environmental cues with rewards (Schultz, 1998), and an 'incentive signal' to mediate the motivational value of reward cues (Berridge and Robinson, 1998). This is of significance in addiction because drug-paired cues generate motivational states that can precipitate or invigorate drug-seeking behavior (Arroyo et al, 1999; Panlilio et al, 1996), and elicit craving and relapse (de Wit and Stewart, 1981; O'Brien et al, 1998; Shaham et al, 2003).

In considering the ability of chronic antipsychotic medication to induce dopamine supersensitivity, the importance of the dopamine system in the processing of reward cues, and the role such cues have in drug-seeking and -taking behavior, we were led to ask the following question: Does chronic antipsychotic treatment, using clinically relevant doses, alter responsiveness to reward cues? We addressed this question by evaluating in rats the effects of chronic haloperidol treatment on the operant pursuit of a reward-associated cue. We compared the effects of continuous haloperidol administration (achieved via subcutaneous (SC) osmotic minipump) vs intermittent administration (achieved via daily SC injection). This is because continuous treatment induces behavioral dopamine supersensitivity, but intermittent treatment does not (Ericson et al, 1996; Samaha et al, 2008). Our findings show that following an acute amphetamine injection, rats with a history of continuous - but not intermittentantipsychotic treatment pursued the reward cue more vigorously than antipsychotic-naïve animals. This was not related to changes in the predictive value of rewardpredicting stimuli, but was potentially linked to the development of behavioral supersensitivity to dopaminergic stimulation, and to increased amphetamine-induced mRNA for the immediate early-genes c-fos and Nur77 in striatopallidal and striatonigral neurons of the caudate-putamen.

\section{SUBJECTS AND METHODS}

\section{Subjects}

Male Sprague-Dawley rats (Charles-River, Montréal, Canada; 200-225 g) were housed two/cage in a vivarium (12-h reverse light/dark cycle. Lights off at $0800 \mathrm{~h}$ ). Testing was conducted during the dark phase of the animals' circadian cycle. Procedures complied with the Université de Montréal's animal care committee.

\section{Drugs}

Haloperidol (HAL; Sabex, Boucherville, Canada) was dissolved in $0.5 \%$ glacial acetic acid/water solution ( $\mathrm{pH} 5$ ) for administration via SC minipump (Alzet model 2ML2, 19-day drug delivery; Durect, Cupertino, CA, USA) because HAL maintains striatal D2 receptor occupancy over time in this vehicle (Kapur et al, 2003; Samaha et al, 2007). For administration through SC injection, HAL was dissolved in $20 \mathrm{mmol} / \mathrm{l}$ phosphate-buffered saline (PBS) because a glacial acetic acid/water solution is very acidic for instant delivery to a single site and could irritate the animals, which were injected daily for 17 days (see below). Importantly, using either PBS (Samaha et al, 2008) or a glacial acetic acid/water solution (Li et al, 2007) does not alter HAL's behavioral effects. D-amphetamine sulfate (AMPH; Sigma-Aldrich, Dorset, UK) was dissolved in $0.9 \%$ saline. All injections were given $\mathrm{SC}$ route in a volume of $1 \mathrm{ml} / \mathrm{kg}$.

\section{Antipsychotic Treatment}

We wished to compare the effects of continuous $v s$ intermittent HAL using clinically meaningful and equivalent doses. Multiple lines of evidence have suggested that doses of antipsychotics that are clinically efficacious occupy a target range of striatal D2 receptors. Although the relationship between the degree of striatal D2 receptor occupancy and the quality of the therapeutic response is complex (Pilowsky et al, 1992; Wolkin et al, 1989), clinical and brain imaging studies have generally supported the idea that for typical antipsychotics, therapeutic efficacy and a reduced risk of motor side effects can be seen with $65-75 \%$ D2 receptor occupancy ((Farde et al, 1992; Kapur et al, 2000), the therapeutic window is reported to lie lower-at 40-60\% - for many atypical antipsychotics (Abi-Dargham and Laruelle, 2005)). Pre-clinical studies with typical antipsychotics also show antipsychotic-like efficacy at doses that provide $65-80 \%$ occupancy and an increased incidence of extra-pyramidal side effects at $>80 \%$ occupancy (Natesan et al, 2006; Wadenberg et al, 2000).

In rats, HAL administration through a minipump produces continuously high levels of striatal D2 occupancy (Kapur et al, 2003; Samaha et al, 2007), whereas SC injections produce transiently high occupancy, which is diminished at $24 \mathrm{~h}$ post injection (Kapur et al, 2003). HAL administration through a minipump in rats, models the kinetics of standard antipsychotic treatment in humans because D2 occupancy in human striatum can remain high for several days following a dose (Farde et al, 1989; Tauscher et al, 2002). To meaningfully compare the continuous (minipump) vs intermittent (SC injection) conditions, we chose doses that held achieved dose/peak D2 occupancy constant under the two conditions. In rats, $0.5 \mathrm{mg} / \mathrm{kg} /$ day HAL via minipump achieves clinically relevant levels of D2 occupancy (73\%; unpublished observations. See also (Kapur et al, 2003; Samaha et al, 2007)). However, when given through SC injection, $0.5 \mathrm{mg} / \mathrm{kg}$ leads to $>80 \%$ D2 occupancy (Wadenberg et al, 2001) and is cataleptogenic (Natesan et al, 2006), and $0.05 \mathrm{mg} / \mathrm{kg}$ is sufficient to produce clinical levels of occupancy without catalepsy $(74 \%, 2 \mathrm{~h}$ post injection (Kapur et al, 2003)). Thus, we studied three groups: CONT-HAL, which received $0.5 \mathrm{mg} / \mathrm{kg} /$ day $\mathrm{HAL}$ through a minipump, INT-HAL, which received $0.05 \mathrm{mg} / \mathrm{kg} /$ day HAL through daily SC injection, and VEH, which received PBS through daily SC injection.

Under $1.5 \%$ isoflurane, CONT-HAL rats were implanted with minipumps as in (Samaha et al, 2008), and INT-HAL 
and VEH animals received an incision, closed with clips. The next day and for 17 consecutive days, the INT-HAL group was injected with HAL and all remaining animals received $\mathrm{PBS}$. On the 18th day, minipumps were removed from CONT-HAL rats. INT-HAL and VEH animals were sham operated.

\section{Experiment 1: Operant Responding for Conditioned Reward and AMPH-induced Locomotion}

Here we assessed HAL-induced effects on operant responding for conditioned reward. We also assessed AMPHinduced locomotion to determine whether responding for conditioned reward was related to the development of dopamine supersensitivity.

Pavlovian conditioning and operant responding for conditioned reward. Procedures are illustrated in Figure 1a. In standard operant chambers (Med Associates, St Albans, VT, USA), water-restricted rats ( $2 \mathrm{~h}$ /day) were trained to associate the delivery of $0.1 \mathrm{ml}$ tap water (the unconditioned stimulus; UCS) into a receptacle with a light/ tone stimulus (the conditioned stimulus; CS) as in (Fletcher, 1995). Animals were then assigned to the VEH, INT-HAL, and CONT-HAL groups. Following antipsychotic treatment cessation, rats received a reminder conditioning session followed by two lever-training sessions in which they could press an 'active' lever to obtain CS presentations (now a conditioned reward) according to a random-ratio 2 schedule, and an 'inactive' lever which produced no consequences. No water was delivered. Sessions ended following 10 active presses or after $40 \mathrm{~min}$. Two conditioned reward tests were then given under the same conditions, but without limiting the number of active lever presses. Immediately before testing, rats were injected with saline (first test) or $0.5 \mathrm{mg} / \mathrm{kg}$ AMPH (second test).

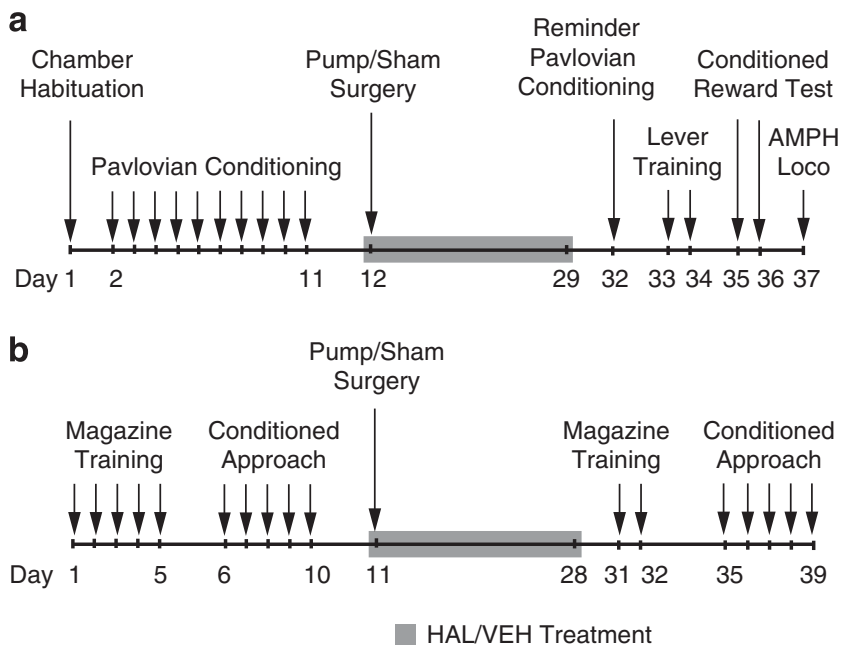

Figure I Timeline of behavioral training, testing, and antipsychotic treatment for Experiment $\mathrm{I}$ (a), in which operant responding for a conditioned reward was assessed following haloperidol (HAL) treatment cessation, and Experiment 2 (b), in which conditioned approach behavior to localizable reward-predicting stimuli was assessed before and starting on the 7th day following HAL treatment cessation. AMPH, amphetamine; Loco, locomotion; VEH, vehicle.
$A M P H$-induced locomotion. One day following conditioned reward testing, AMPH $(1.5 \mathrm{mg} / \mathrm{kg})$-induced locomotion was measured in Plexiglas cages as was measured in (Samaha et al, 2007).

\section{Experiment 2: Conditioned Approach Behavior to a Reward-predicting Cue}

A reward cue more effectively reinforces an operant response in animals with a propensity to approach localizable conditioned stimuli (Robinson and Flagel, 2009). Thus, we determined whether HAL-induced changes in operant responding for conditioned reward could involve changes in approach behavior to reward-predicting stimuli. In the presence of a reward cue, some rats preferentially approach/engage with the cue ('sign trackers'), whereas others preferentially approach the location of reward delivery ('goal trackers'; (Flagel et al, 2007)). We determined which rats are goal trackers and which are sign trackers before assessing HAL-induced changes in signtracking $v s$ goal-tracking conditioned responses.

Conditioned approach behavior. Procedures are illustrated in Figure 1b. Food-restricted rats were given once-daily magazine-training sessions ( $\sim 25$-min) for 5 days, where 50 banana-flavored food pellets (VWR, Ville Mont-Royal, Canada) were delivered into a recessed magazine on a variable interval 90 -s schedule. All rats ate most pellets by the 5th day. We then assessed conditioned approach behavior in daily, 35-40 min autoshaping sessions for 5 days (25 trials/session), as in (Flagel et al, 2007). On each trial, the left lever was extended into the chamber for $8 \mathrm{~s}$ (the CS). This was followed by the delivery of one bananaflavored pellet (the UCS). We recorded lever contacts and magazine entries during the CS. As in (Flagel et al, 2007), CS-UCS pairings led to conditioned approach behaviors consisting of lever contacts and magazine entries. Rats in the top $33 \%$, based on average lever contacts during autoshaping, were categorized as sign trackers and rats in the bottom 33\% were categorized as goal trackers (Flagel et al, 2007). Sign and goal trackers were distributed equally in the CONT-HAL, INT-HAL, and VEH groups. Following antipsychotic treatment cessation, rats were given two reminder magazine-training sessions. Conditioned approach behavior was then re-assessed daily for 5 days. On days 4 and 5 , rats were injected with saline or $0.5 \mathrm{mg} / \mathrm{kg} \mathrm{AMPH,}$ 5 min before testing.

\section{Experiment 3: $C$-fos and Nur77 mRNA}

We used in situ hybridization techniques to examine the effects of HAL on AMPH-induced neuronal activation by quantifying $c$-fos and Nur77 mRNA in cortical and striatal regions.

Procedures. At 9 and 10 days following HAL treatment cessation, rats from each group were injected with $1.5 \mathrm{mg} / \mathrm{kg}$ AMPH or saline in the home cage and decapitated $1 \mathrm{~h}$ later. Brains were extracted, frozen in isopentane on dry ice, and stored $\left(-80^{\circ} \mathrm{C}\right)$. Simultaneous radioactive $\left(\left[{ }^{35} \mathrm{~S}\right] \mathrm{UTP}\right.$ labeled Nur77 or c-fos riboprobe) and nonradioactive (digoxygenin-labeled preproenkephalin riboprobe) 
hybridizations were performed on cryostat-cut coronal brain sections $(12-\mu \mathrm{m})$, as in (Beaudry et al, 2000; Tremblay et al, 1999). An experimenter, blind to condition, translated optical gray densities from autoradiographs into $\mu \mathrm{Ci} / \mathrm{g}$ of tissue using a ${ }^{14} \mathrm{C}$ standard curve (ARC-146A, American Radiolabeled Chemicals, St Louis, MI, USA) and ImageJ software (NIH, Bethesda, MD, USA). Background values obtained from the corpus callosum of each section were subtracted from analysis. mRNA levels were measured in caudate-putamen quadrants at $+1.6,+1.2,+0.8,+0.4$, and $0.0 \mathrm{~mm}$ relative to Bregma, the nucleus accumbens $(+2.0,+1.2$, and $+0.8 \mathrm{~mm})$, the prelimbic and infralimbic cortices $(+2.6 \mathrm{~mm})$, and the orbitofrontal cortex $(+3.0 \mathrm{~mm})$ according to (Paxinos and Watson, 1986).

The greatest group differences in AMPH-induced gene expression were observed in the dorsal caudate-putamen $(+0.8 \mathrm{~mm})$. Approximately $95 \%$ of caudate-putamen cells are medium-sized spiny neurons forming the striatopallidal and striatonigral pathways. Striatopallidal cells preferentially express preproenkephalin mRNA $(\mathrm{ENK}+)$ and project to the lateral globus pallidus, whereas striatonigral cells do not preferentially express preproenkephalin mRNA (ENK-), and project to the medial globus pallidus and substantia nigra (Gerfen, 1992). To identify the cellular circuits in which HAL treatment could influence the neurobehavioral response to AMPH, we examined AMPHinduced c-fos and Nur77 mRNA in ENK + and ENK - cells. This was achieved by manually counting seven cell types in three fields $\left(0.26 \mathrm{~mm}^{2} /\right.$ field $)$ of the dorsolateral (DL) caudate-putamen: cells containing mRNA for $c$-fos, Nur77 or ENK, both $c$-fos or Nur77 and ENK, and $c$-fos or Nur77 without ENK. Quantification was carried out at $\times 400$ using an optical microscope (Carl Zeiss, Montréal, Canada).

\section{Statistics}

Lever presses in Experiment 1 were analyzed with three-way ANOVA. When interaction effects were significant, simple effects were analyzed using the Bonferonni test. Withingroup AMPH vs saline effects on lever pressing were analyzed using paired $t$-tests. Conditioned approach behaviors and $\mathrm{AMPH}$-induced locomotion were analyzed using two-way ANOVA. AMPH effects on conditioned approach behaviors were analyzed using one-way ANOVA followed by Tukey's Multiple Comparison Test (TMCT). mRNA levels and counted cells were analyzed using one-way ANOVA followed by TMCT.

\section{RESULTS}

\section{Experiment 1: Operant Responding for Conditioned Reward and AMPH-Induced Locomotion}

Following antipsychotic treatment cessation, rats were given a 'reminder' Pavlovian conditioning session. During this session, all groups nose-poked more into the magazine containing the water receptacle during the 5 -s CS period than in the 5-s period before the onset on the CS (PCS), and this behavior did not differ between groups (data not shown; one-way ANOVA on average CS/PCS ratio; $\mathrm{F}(2$, $39)=1.1, p=0.35)$. This indicates that rats in all groups retained the CS-UCS contingency. As shown in Figure 2, all

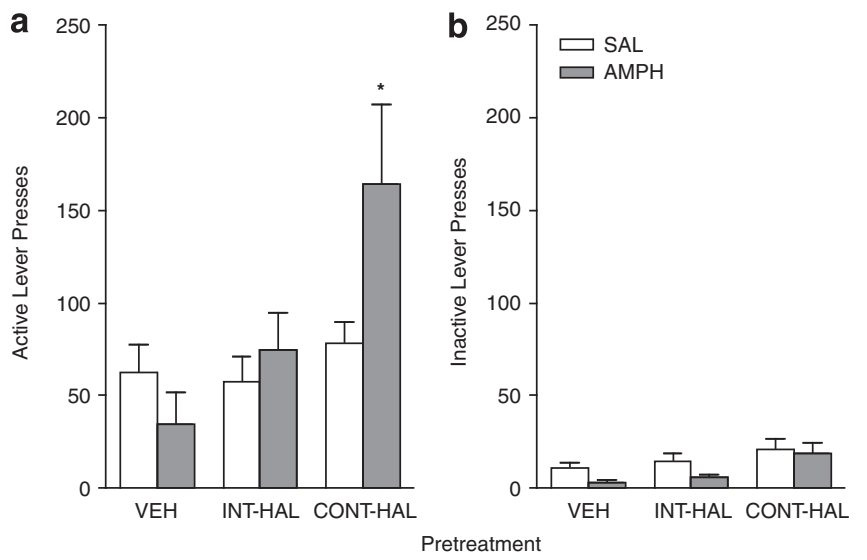

Figure 2 Continuous (CONT-HAL), but not chronic and intermittent (INT-HAL) haloperidol (HAL), treatment enhances operant responding for a conditioned reward following an injection of amphetamine $(0.5 \mathrm{mg} / \mathrm{kg})$. $n ' s=14$ per condition. Presses on the active lever are shown in (a) and presses on the inactive lever are shown in (b). CONT-HAL, group receiving $0.5 \mathrm{mg} / \mathrm{kg} /$ day haloperidol through minipump; INT-HAL, group receiving $0.05 \mathrm{mg} / \mathrm{kg} /$ day haloperidol through daily subcutaneous injection. $* p<0.05$ compared with vehicle (VEH)

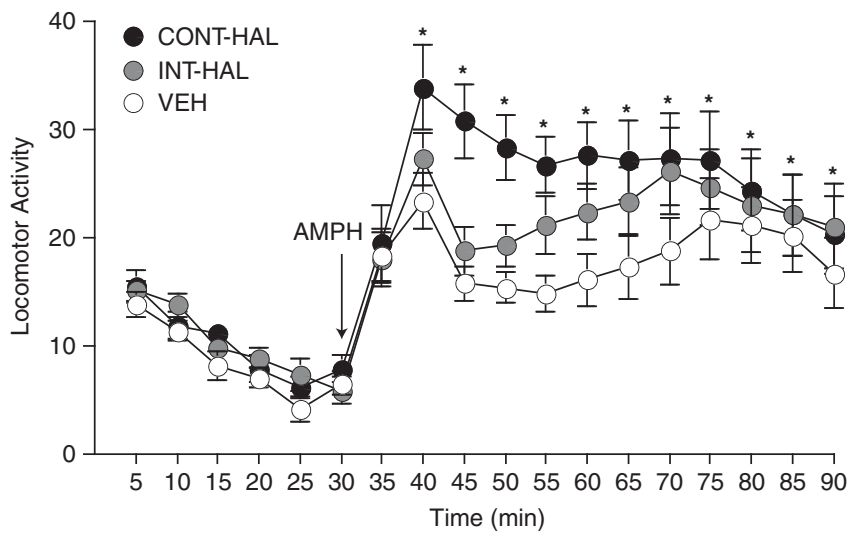

Figure 3 Continuous (CONT-HAL), but not chronic and intermittent (INT-HAL) haloperidol (HAL), treatment enhances the locomotor response to amphetamine $(1.5 \mathrm{mg} / \mathrm{kg})$. $n$ 's $=14$ per condition. CONT-HAL, group receiving $0.5 \mathrm{mg} / \mathrm{kg} /$ day haloperidol through minipump; INT-HAL, group receiving $0.05 \mathrm{mg} / \mathrm{kg} /$ day haloperidol through daily subcutaneous injection. $* p<0.05$ compared with vehicle (VEH). AMPH, amphetamine.

groups pressed more on the active (A) $v$ s inactive (B) lever $(\mathrm{F}(1,39)=41.18, p<0.0001)$. This indicates that all groups discriminated between the two levers and spontaneously acquired a new operant response, reinforced solely by the conditioned reward. There was a significant GroupInjection $\times$ Lever interaction $(\mathrm{F}(2,39)=4.39, p=0.019)$. Post hoc investigation of this interaction revealed that following amphetamine, active lever presses were greater in the CONT-HAL group relative to the VEH group $(p=0.009)$. The INT-HAL group was not different from the VEH group $(p=1.00)$. Following amphetamine, inactive lever presses were also greater in the CONT-HAL group relative to both the INT-HAL and VEH groups $(p$ 's $<0.05)$. However, AMPH did not alter inactive lever presses in the CONT-HAL rats compared with saline $(t=0.33, p=0.75)$. There were no group differences in either active or inactive lever presses following an injection of saline (all $p$ 's $>0.05$ ). 
a

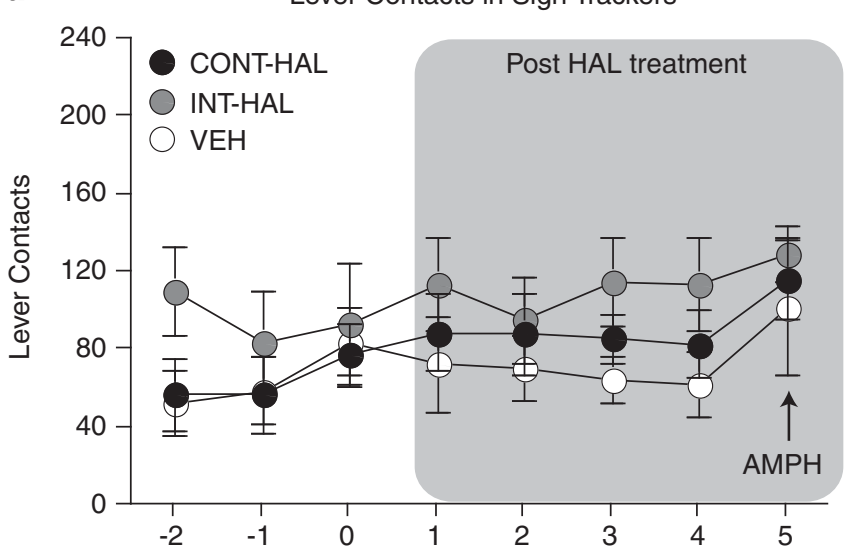

b Magazine Entries in Goal Trackers

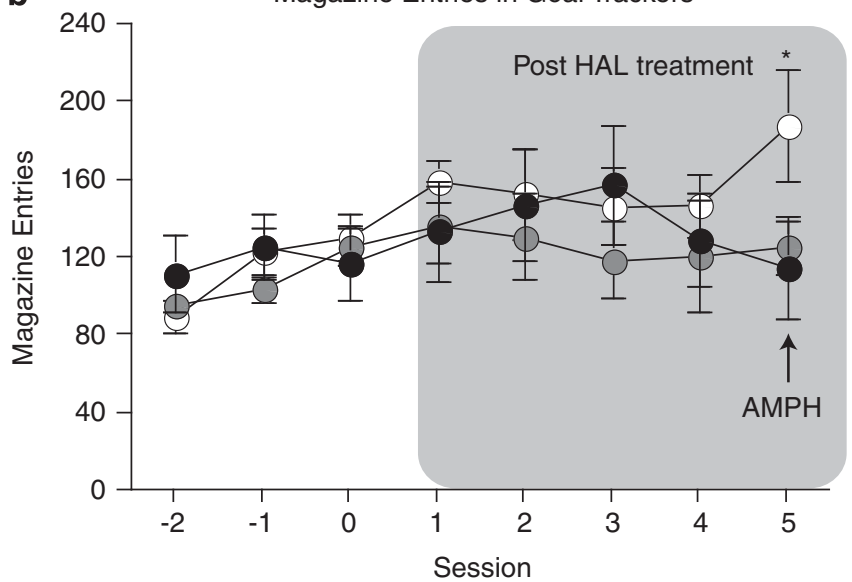

Figure 4 Neither continuous (CONT-HAL) nor chronic and intermittent (INT-HAL) haloperidol (HAL) treatment altered conditioned stimulus-directed (a) or goal-directed (b) conditioned approach responses. n's $=6-7$ per condition. CONT-HAL, group receiving $0.5 \mathrm{mg} / \mathrm{kg} /$ day haloperidol through minipump; INT-HAL, group receiving $0.05 \mathrm{mg} / \mathrm{kg} /$ day haloperidol through daily subcutaneous injection. $* p<0.05$ compared with CONT-HAL and INT-HAL. AMPH, amphetamine.

AMPH-induced locomotion was greater in CONT-HAL compared with VEH (Figure 3; main effect of Group between $40-90 \mathrm{~min} ; \mathrm{F}(1,26)=5.56, p=0.03)$. INT-HAL rats were no different from VEH rats $(p>0.05)$.

\section{Experiment 2: Conditioned Approach Behavior to a Reward-Predicting Cue}

Figure 4 shows conditioned approach behavior in sign trackers (a) and goal trackers (b) before antipsychotic treatment (sessions $-2,-1$, and 0 ) and following antipsychotic treatment cessation (sessions 1-5). Regardless of the mode of treatment (continuous $v s$ intermittent) and of the nature of the conditioned response (sign tracking $v s$ goal tracking), previous antipsychotic exposure did not alter approach behavior to a conditioned stimulus (sessions 1 to 4 , main effect of Group; (a), $p=0.31$; (b), $p=0.73$ ). Acute AMPH did not influence sign-tracking behavior in any group ( $(\mathrm{A})$, session $5, p>0.05)$, but it increased goaltracking behavior in VEH compared with CONT-HAL and INT-HAL rats $((B)$; session $5, \mathrm{~F}(2,16)=5.84$, all $p$ 's $<0.05)$.
Supplementary Figure 1 shows lever contacts in goal trackers (a) and magazine entries in sign trackers (b), both before antipsychotic treatment (sessions $-2,-1$, and 0 ) and following antipsychotic treatment cessation (sessions 1-5). Antipsychotic treatment had no effect on either the number of lever contacts in goal trackers ((A) sessions $1-4, p>0.05)$ or the number of magazine entries in sign trackers ((b) sessions $1-4, p>0.05)$. Furthermore, acute AMPH did not influence these behaviors ((a) and (b), session 5, all p's >0.05).

\section{Experiment 3: $C$-fos and Nur77 mRNA}

There were no group differences in AMPH-induced Nur77 or c-fos mRNA expression in any cortical region analyzed (data not shown, all $p$ 's $>0.05$ ). Supplementary Table S1 shows saline- vs AMPH-induced c-fos mRNA in the nucleus accumbens core and shell averaged from +2.0 to $0.8 \mathrm{~mm}$ relative to Bregma. There were no group differences in saline-induced c-fos mRNA in either the nucleus accumbens core or shell (data not shown, all $p$ 's $>0.05$ ). Thus, salinetreated rats were pooled to form a single SAL group for each subdivision. All AMPH-treated groups had greater c-fos mRNA expression than SAL (all p's $<0.001$ ), and there was no effect of antipsychotic treatment. Similar results were seen with Nur77 (data not shown). Supplementary Table S2 shows saline- vs AMPH-induced Nur77 mRNA expression in the quadrants of the caudate-putamen (dorsomedial (DM), DL, ventromedial (VM), and ventrolateral (VL)), averaged from +1.6 to $0 \mathrm{~mm}$ relative to Bregma. AMPHinduced Nur77 mRNA was greater in CONT-HAL relative to the other AMPH-treated groups in all quadrants but the VM $(\mathrm{DM}, \mathrm{F}(2 ; 96)=8.96, \mathrm{DL}, \mathrm{F}(2 ; 96)=7.7, \mathrm{VL}, \mathrm{F}(2,96)=5.33$; all $p$ 's $<0.05)$. In addition, saline-induced Nur77 expression was decreased in INT-HAL relative to the other saline-treated groups in all quadrants (all $p$ 's $<0.05$ ). Similar results were seen with c-fos mRNA (Supplementary Table S3).

The greatest group differences in AMPH-induced gene expression in the caudate-putamen were seen at level + $0.8 \mathrm{~mm}$ relative to Bregma. These results are shown in Figures 5-7. There were no group differences in salineinduced Nur77 or c-fos mRNA in any quadrant of the caudate-putamen (data not shown, all $p$ 's $>0.05$ ). Thus, saline-treated rats were pooled to form a single SAL group for Nur77 (Figure 5) and for c-fos (Figure 6) mRNAs. As shown in Figure 5, all AMPH-injected groups had greater Nur77 mRNA expression than SAL in the DM and in the VM caudate-putamen $(\mathrm{DM}, \mathrm{F}(3,47)=22.54, \mathrm{VM}, \mathrm{F}(3$, $47)=29.05$; all $p$ 's $<0.05)$. In addition, there were group differences in amphetamine-induced Nur77 mRNA. In the DL and in VL caudate-putamen, AMPH enhanced Nur77 mRNA expression above SAL only in CONT-HAL rats (DL, $\mathrm{F}(3,47)=6.76, \mathrm{VL}, \mathrm{F}(3,47)=4.98$; all $\left.p^{\prime} \mathrm{s}<0.05\right)$. In addition, in the DM quadrant, AMPH-induced Nur77 mRNA levels were greater in CONT-HAL rats than in $\mathrm{VEH}$ or in INT-HAL rats (all $p$ 's $<0.01$ ). In the VM and VL quadrants, AMPH-induced Nur77 mRNA levels were also greater in CONT-HAL than in INT-HAL rats (all $p$ 's $<0.05$ ). No other comparisons were significant.

As shown in Figure 6, all AMPH-treated groups had greater c-fos mRNA levels relative to SAL in all quadrants of the caudate-putamen $(\mathrm{DM}, \mathrm{F}(3,47)=31.7, \mathrm{DL}, \mathrm{F}(3$, $47)=20.2$, VM, F $(3,47)=38.2$, and VL, $\mathrm{F}(3,47)=18.3$; all 

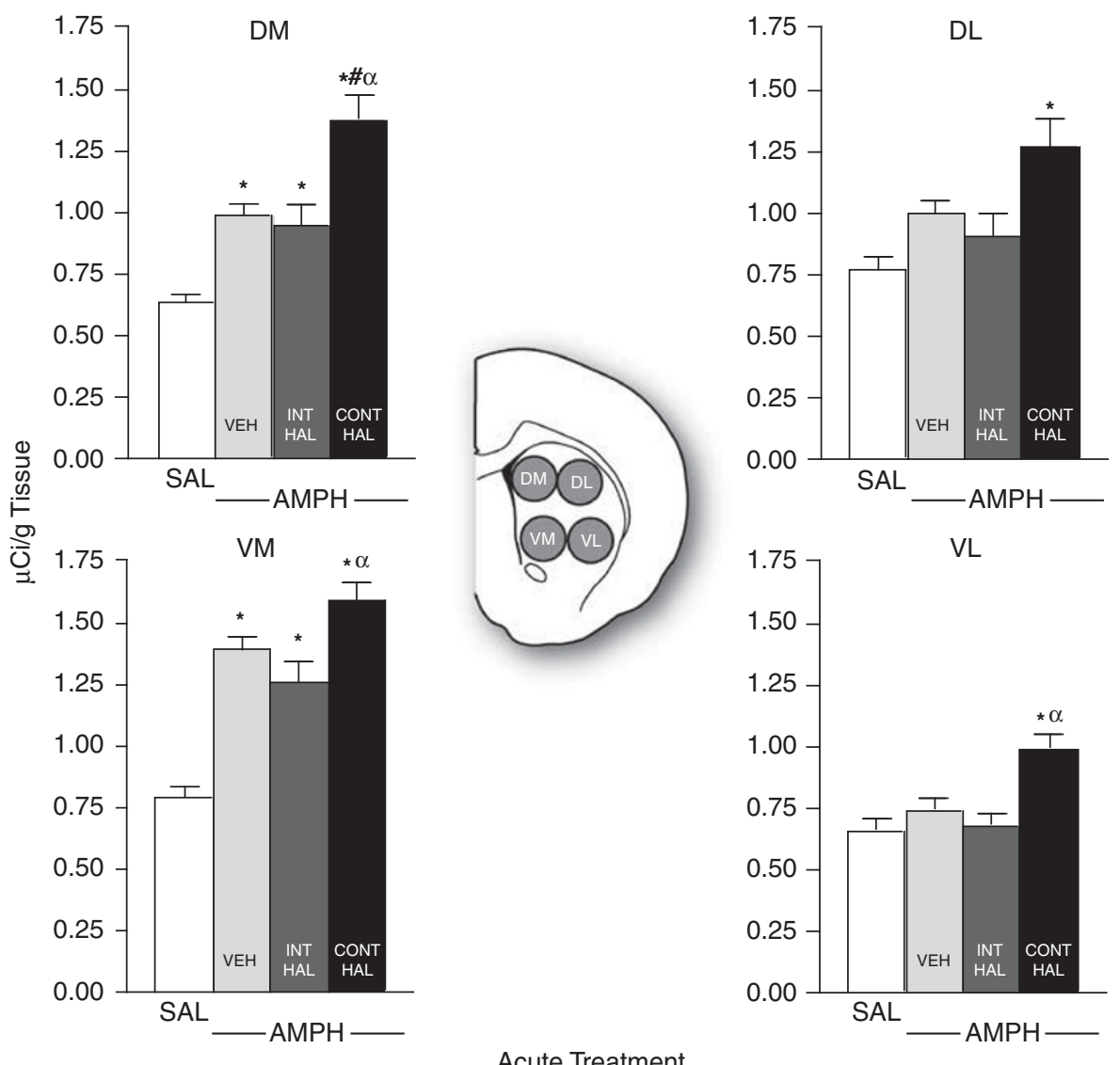

Figure 5 Continuous (CONT-HAL), but not chronic and intermittent (INT-HAL), haloperidol (HAL) treatment potentiates amphetamine-induced Nur77 mRNA expression in the caudate-putamen. n's $=24$ in the SAL condition, and 9 per condition in remaining groups. CONT-HAL, group receiving $0.5 \mathrm{mg} / \mathrm{kg} /$ day haloperidol through minipump; INT-HAL, group receiving $0.05 \mathrm{mg} / \mathrm{kg} /$ day haloperidol through daily subcutaneous injection; SAL, combined control group receiving saline. ${ }^{*} p<0.05$ compared with SAL, ${ }^{*} p<0.05$ compared with $V E H,{ }^{\alpha} p<0.05$ compared with INT-HAL. AMPH, amphetamine; $\mathrm{DL}$, dorsolateral; DM, dorsomedial; VL, ventrolateral; VM, ventromedial.

p's $<0.05)$. In addition, AMPH-induced c-fos mRNA expression was greater in CONT-HAL rats relative to $\mathrm{VEH}$ control rats in the DM, DL, and in VL quadrants (all $p$ 's $<0.05)$. In the VL quadrant, c-fos mRNA expression was also greater in CONT-HAL than in INT-HAL rats $(p<0.01)$. No other comparisons were significant.

Figure 7 shows AMPH-induced c-fos and Nur77 mRNA expression in ENK + and ENK-cells. There were no group differences in the number of any cell type following saline. Thus, all saline-injected rats were pooled to form a single SAL control group for each cell type (panels a-f). The effects of AMPH on $c$-fos and Nur77 mRNA expression depended upon previous antipsychotic treatment. AMPH increased the number of each cell type relative to SAL only in CONTHAL rats, and the number of each cell type following AMPH was greater in CONT-HAL rats than in VEH or in INT-HAL rats $((\mathrm{a}), \mathrm{F}(3,40)=13.71 ;(\mathrm{b}), \mathrm{F}(3,40)=7.86 ;$ (c), $\mathrm{F}(3$, $38)=13.70 ;(d), F(3,41)=6.81 ;(e), F(3,41)=8.53$; with the exception of $(\mathrm{f})$, in which CONT-HAL $>\mathrm{VEH}$ only, $\mathrm{F}(3$, $41)=5.52$; all p's $<0.0004)$.

\section{DISCUSSION}

We show here that a history of continuous exposure to haloperidol, potentiates instrumental responding for a reward cue (a light-tone stimulus paired with water) following an amphetamine challenge, and that this effect is not seen following a history of chronic, but intermittent antipsychotic exposure. This effect of continuous antipsychotic treatment was observed using a clinically relevant dose and mode of administration, was behaviorally specific (responding on an inactive lever was unaffected), and was persistent-lasting for at least 1 week following the cessation of antipsychotic administration. Consistent with previous work (Mead et al, 2004; Robbins, 1978; Robbins et al, 1983), the dose of amphetamine used here $(0.5 \mathrm{mg} / \mathrm{kg})$ had no effect on operant responding for conditioned reward in vehicle-treated control animals. However, this dose potentiated responding for a conditioned reward in rats with a history of continuous exposure to antipsychotic medication. The ability of previous continuous antipsychotic treatment to enhance amphetamine-induced potentiation of conditioned reward was potentially linked to the development of behavioral supersensitivity to dopaminergic stimulation, because continuous (but not intermittent) treatment also induced an exaggerated psychomotor response to amphetamine. Importantly, the two modes of antipsychotic treatment led to different outcomes in spite of the fact that achieved dose, peak levels of striatal D2 receptor occupancy, duration, and route of administration were identical under the two conditions. We have shown previously that the ability of continuous, but not intermittent, 

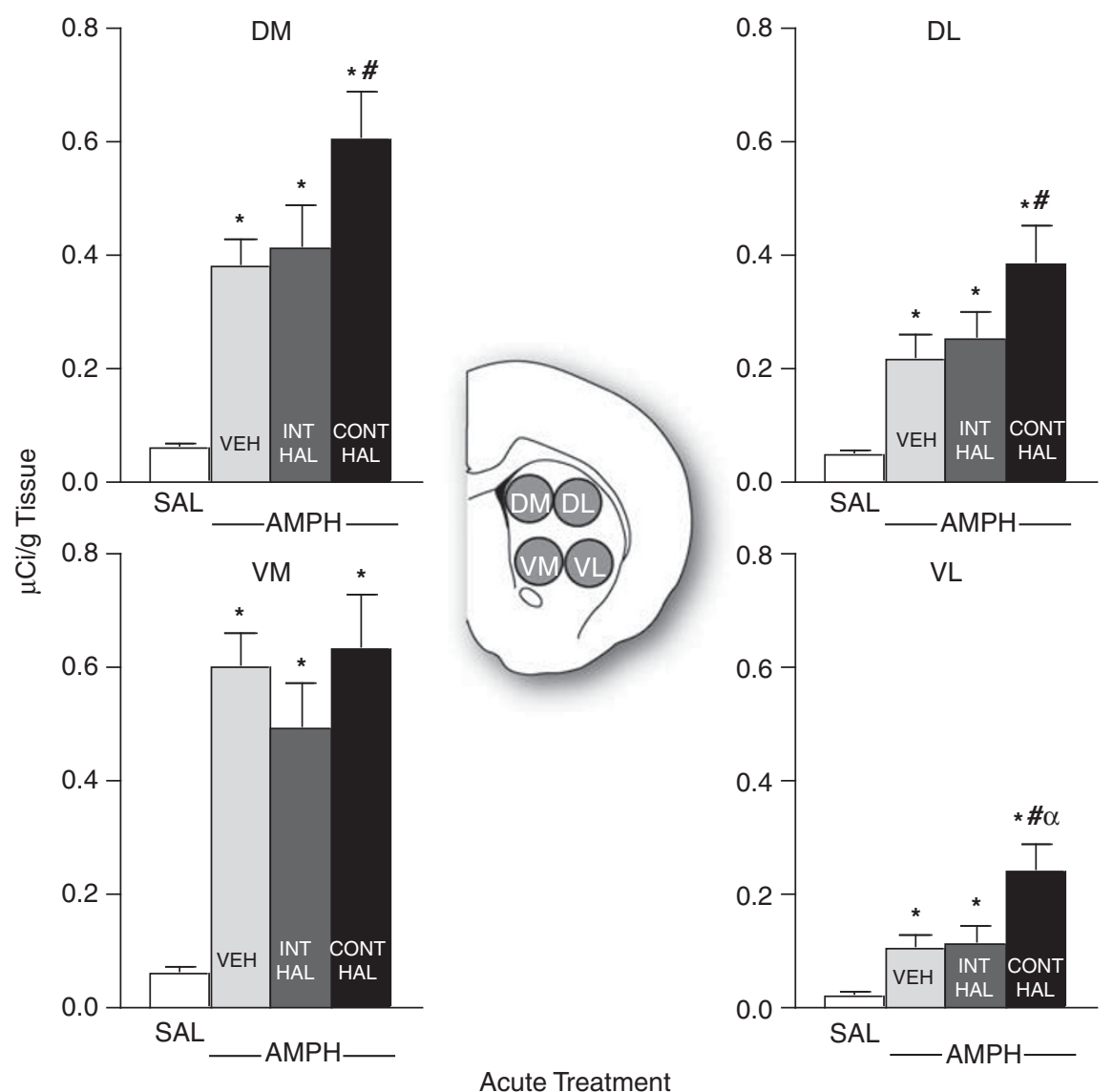

Figure 6 Continuous (CONT-HAL), but not chronic and intermittent (INT-HAL), haloperidol (HAL) treatment potentiates amphetamine-induced c-fos mRNA expression in the caudate-putamen. $n^{\prime} \mathrm{s}=24$ in the SAL condition, and 9 per condition in remaining groups. CONT-HAL, group receiving $0.5 \mathrm{mg} / \mathrm{kg} /$ day haloperidol via minipump; INT-HAL, group receiving $0.05 \mathrm{mg} / \mathrm{kg} /$ day haloperidol via daily subcutaneous injection; $\mathrm{SAL}$, combined control group receiving saline. ${ }^{*} p<0.05$ compared with SAL, ${ }^{*} p<0.05$ compared with VEH, ${ }^{\alpha} p<0.05$ compared with INT-HAL. AMPH, amphetamine; DL, dorsolateral; DM, dorsomedial; $\mathrm{VL}$, ventrolateral; $\mathrm{VM}$, ventromedial.

antipsychotic treatment to induce a state of behavioral supersensitivity to dopamine is associated with decreased efficacy in animal models of antipsychotic-like effects (Samaha et al, 2007, 2008). The current findings extend this previous work by showing that antipsychotic-induced behavioral supersensitivity to dopamine could also lead to changes in reward function.

A reward cue is a more effective conditioned reinforcer in animals that have a greater propensity to attribute predictive value to and approach localizable conditioned stimuli (Robinson and Flagel, 2009). As such, we speculated that continuous antipsychotic treatment could augment amphetamine-induced operant responding for a reward cue by increasing the propensity to attribute predictive value to and approach reward cues. However, using Pavlovian autoshaping procedures, we found that neither continuous nor intermittent antipsychotic treatment altered basal, or amphetamine-induced approach of a conditioned stimulus (sign tracking; Flagel et al, 2007, 2008). Thus, a history of continuous (but not intermittent) antipsychotic treatment enhances the ability of reward cues to reinforce the learning of new actions following an acute amphetamine challenge (Experiment 1), but it does not necessarily alter the ability of such cues to attract (Experiment 2). This is not the first time that a dissociation between the incentive $v s$ predictive properties of reward cues has been reported (Robinson and Flagel, 2009). These two properties of reward cues have overlapping but also potentially distinct neural underpinnings. For example, although the ability of stimuli that have been paired with a reward to acquire predictive properties and elicit approach (ie, elicit sign-tracking behavior) depends on the nucleus accumbens, lesions of nucleus accumbens sub-regions do not completely abolish operant responding for such stimuli (Parkinson et al, 1999). Thus, it is possible that a history of continuous exposure to antipsychotic medication preferentially alters the neural substrates that mediate the incentive properties of reward cues $v s$ the substrates that mediate their predictive properties.

It has previously been shown that chronic antipsychotic treatment disrupts the acquisition of sign-tracking behavior (Danna and Elmer, 2010). Our findings extend this work by showing that previous antipsychotic treatment does not affect the expression of previously learned sign-tracking behavior. HAL treatment did however have a modest effect on the expression of another form of conditioned approach behavior; approach of the site of reward delivery (goal tracking). Following acute amphetamine, goal-tracking behavior was modestly but significantly increased in control rats relative to both antipsychotic-treated groups. This 


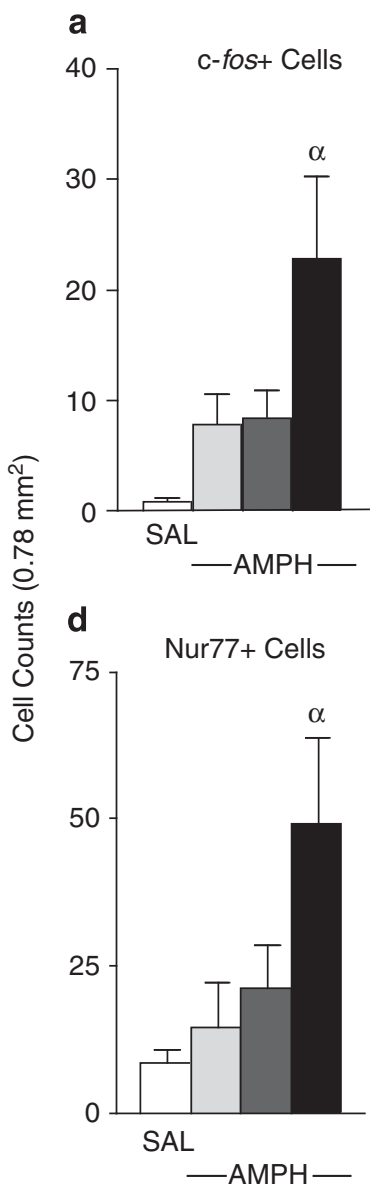

b

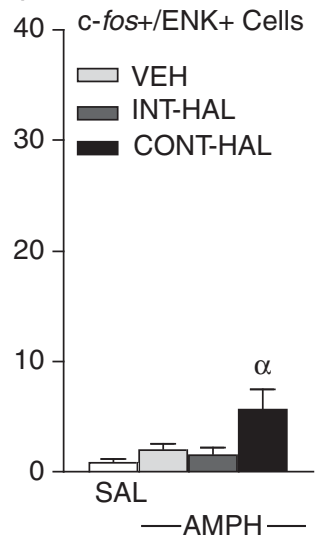

e

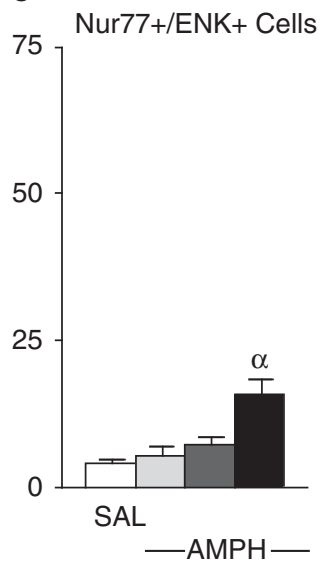

C

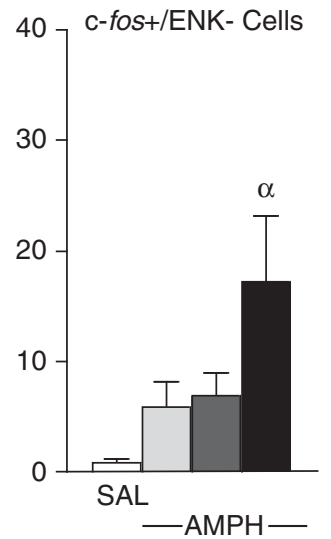

f

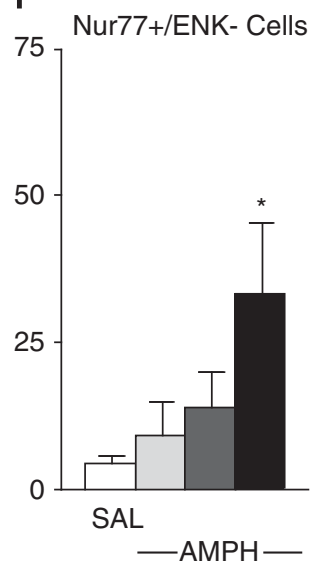

Acute Treatment

Figure 7 Continuous (CONT-HAL) but not chronic and intermittent (INT-HAL) HAL treatment potentiates amphetamine-induced c-fos and Nur77 mRNA expression in both preproenkephalin-containing (ENK +; (b) and (e), respectively) and preproenkephalin-lacking (ENK-; (c) and (f), respectively) cells of the caudate-putamen. n's $=23-24$ in the SAL condition, and 6-9 per condition in remaining groups. CONT-HAL, group receiving $0.5 \mathrm{mg} / \mathrm{kg} / \mathrm{day}$ haloperidol via minipump; INT-HAL, group receiving $0.05 \mathrm{mg} / \mathrm{kg} /$ day haloperidol via daily subcutaneous injection; SAL, combined control group receiving saline. *Indicates $p<0.05$ compared to SAL and VEH, ${ }^{\alpha}$ indicates $p<0.05$ compared to SAL, VEH and INT-HAL. AMPH, amphetamine; ENK, preproenkephalin.

effect of amphetamine is consistent with previous work (Holden and Peoples, 2010). One possible explanation for the lack of effect of amphetamine in antipsychotic-treated rats is that a history of chronic antipsychotic exposure might alter the brain substrates underlying the expression of goaltracking behavior. These substrates could include altered levels of tyrosine hydroxylase, dopamine transporter, and D2 mRNA in mesolimbic structures (Flagel et al, 2007).

To investigate the neural mechanisms by which continuous antipsychotic treatment might enhance amphetamineinduced potentiation of conditioned reward, we assessed amphetamine-induced gene regulation in brain circuits that mediate incentive motivation for reward cues. We found that a history of continuous, but not intermittent, antipsychotic treatment intensified amphetamine-induced c-fos and Nur77 mRNA expression in striatopallidal and striatonigral cells of the caudate-putamen. C-fos and Nur77 are immediate early genes that rapidly respond to changes in cell activity. Both genes transform acute cellular events into lasting changes in cell function by regulating the transcription of late-onset genes (Levesque and Rouillard, 2007; Robertson et al, 1991). Thus, our findings indicate that continuous exposure to antipsychotic medication induces lasting changes in both the behavioral and neurobiological impact of amphetamine. It is not known whether there is a causal relationship between the ability of amphetamine to engage caudate-putamen neurons and its ability to potentiate conditioned reward. However, several lines of evidence support the idea that the actions of amphetamine within the caudate-putamen mediate, at least in part, the drug's effects on the operant pursuit of conditioned reward. First, intra-caudate infusions of amphetamine are sufficient to enhance operant responding for conditioned reward (Taylor and Robbins, 1984). Second, dopamine neurotransmission within the caudate-putamen is thought to provide an incentive motivational signal that directs attention and behavior towards reward-predicting cues (Palmiter, 2008). On the basis of these observations, we speculate that in individuals with a history of continuous antipsychotic treatment, dopaminergic stimulation (achieved here by an amphetamine challenge), could lead to altered signaling in the caudate-putamen-possibly through changes in D2 receptor number and function (Ginovart et al, 2009; Samaha et al, 2007, 2008) - and that this in turn could lead to aberrant assignment of incentive motivational value to reward cues. 
It is of particular note that continuous haloperidol treatment augmented amphetamine-induced gene expression in striatopallidal cells. Amphetamine is often reported to induce immediate early gene expression in striatonigral cells, with little if any expression in striatopallidal cells - particularly when amphetamine is given in the animal's home cage as was done here (Berretta et al, 1992; Cenci et al, 1992; Johansson et al, 1994; Ruskin and Marshall, 1994). However, more recent work shows that when administered under conditions that promote sensitization to the behavioral effects of the drug (eg, in a novel environment), amphetamine does induce c-fos expression in striatopallidal cells (Badiani et al, 1999; Uslaner et al, 2001).

Does continuous HAL exposure enhance the effects of amphetamine on conditioned reward, on locomotion, and on gene regulation through pre- or post-synaptic processes? This question is an important avenue for future research. Pre-synaptic mechanisms could involve changes in dopamine release or reuptake, or both. Post-synaptic mechanisms could involve modifications in post-synaptic receptor number and/or sensitivity that could in turn lead to changes in the post-synaptic, intra-cellular response to amphetamine. Although this issue remains to be resolved, there are several reasons to suspect preferential involvement of postrather than pre-synaptic mechanisms. First, a history of chronic antipsychotic treatment enhances the behavioral and neurobiological effects of amphetamine without a pre-synaptic increase in amphetamine-induced dopamine availability in the striatum (Compton and Johnson, 1989; Ichikawa and Meltzer, 1992; See et al, 1992). Second, chronic HAL treatment increases both the number and sensitivity of striatal D2/3 receptors (Ginovart et al, 2009; Samaha et al, 2007, 2008). Though these studies did not determine on which side of the synapse these $\mathrm{D} 2 / 3$ receptor changes were located, the ability of pre-synaptic autoreceptors to regulate dopamine overflow is unchanged following chronic HAL treatment (administered through the oral route; Chesi et al, 1995). Third, chronic HAL exposure augments the locomotor response to intra-accumbens or intra-caudate-putamen infusions of dopamine (Halperin et al, 1983). Finally, our current gene findings demonstrate that a history of continuous HAL treatment alters the post-synaptic, intra-cellular signaling cascades engaged by amphetamine. Taken together, these observations suggest that post-synaptic neuroadaptations likely underlie the ability of continuous antipsychotic treatment to enhance the behavioral and neurobiological response to amphetamine.

Why does a history of continuous, but not intermittent, antipsychotic treatment enhance the ability of amphetamine to potentiate the incentive motivational properties of a reward cue? We hypothesize that by continuously occupying D2 receptors, continuous antipsychotic treatment involves unrelenting perturbation of normal dopamine neurotransmission. This elicits compensatory neuroadaptations, including increased striatal D2 receptor number and function (Ginovart et al, 2009; Samaha et al, 2007, 2008), and altered amphetamine-induced gene regulation in striatopallidal and striatonigral circuits (present study). Our findings suggest that a functional consequence of these neuroadaptations could be a dopamine supersensitive state and hypersensitivity to reward following dopaminergic stimulation (achieved here through an acute amphetamine injection). In contrast, by occupying D2 receptors for only a few hours in a 24-h period, intermittent treatment might prevent supersensitivity-related neuroadaptations and altered reward processing. Regardless of the precise underlying mechanisms, the present findings suggest that some form of regular, but intermittent, treatment strategy, which would include fixed drug-free periods, should be entertained in some schizophrenia patients vulnerable to drug abuse or addiction. The clinical reality is complex and this makes it difficult to specify exactly what intermittent human regimen should be inferred from the present data. However, a potential approach - and one that would be similar to the intermittent model used in the current study-might be regular dosing with short inter-dosing intervals. This has recently been attempted successfully in patients in a study showing that clinical efficacy can be maintained by extending antipsychotic dosing from everyday to every 2 days (Remington et al, 2005). The authors of this last study have now replicated these initial findings in a larger-scale, double-blind study (Remington et al, 2010). Indeed, intermittent antipsychotic dosing regimens are drawing increasing clinical attention (Remington, 2010).

An important consideration is that we have assessed conditioned reward function at a time when animals were withdrawn from antipsychotic treatment. Altered reward processing (as evidenced for example by compulsive drug use in schizophrenia) can certainly co-occur with antipsychotic treatment. However, the majority of patients with schizophrenia frequently cease antipsychotic treatment for various periods of time (Perkins, 1999), particularly patients who abuse drugs (Owen et al, 1996). Our findings are relevant to understanding changes in reward-directed behavior during such periods of withdrawal from antipsychotic drugs. Another issue that arises from the present findings is whether similar alterations in amphetamineinduced conditioned reward function and gene regulation would be seen following chronic exposure to an atypical antipsychotic, as atypical antipsychotics are now more widely used in the clinic. Work is underway in our laboratory to address this question.

In summary, our findings show (a) that exposure to a clinically representative dose and mode of antipsychotic treatment (modeled here by the continuous treatment condition) enhances the ability of amphetamine to potentiate the incentive motivational properties of a reward cue and intensifies amphetamine-mediated gene regulation in striatopallidal and striatonigral circuits, and (b) these neuroadaptations do not occur if antipsychotic treatment is given intermittently, such that disruption of dopamine neurotransmission is regular, but fixed and finite in time. This work has two major implications. First, it suggests that current antipsychotic treatment strategies, which involve chronic and continuous medication, might alter reward processing in ways that could contribute to compulsive drug seeking and taking. Second, our findings suggest that intermittent treatment strategies merit exploration in schizophrenic patients at risk for drug addiction.

\section{ACKNOWLEDGEMENTS}

This research was supported by a grant from the National Science and Engineering Research Council to ANS (Grant 
No. 355923) and a salary award from the Fonds de la Recherche en Santé du Québec to ANS (Grant No. 16193). We are grateful to Dr Paul Fletcher for procedural advice on the operant responding for conditioned reward paradigm. We thank Drs Shelly Flagel and Terry E Robinson for advice on the Pavlovian conditioned approach paradigm as well as for critical reviews of earlier versions of this manuscript. We thank Dr Guy Rousseau for help with statistical analyses.

\section{DISCLOSURE}

The authors declare no conflict of interest.

\section{REFERENCES}

Abi-Dargham A, Laruelle M (2005). Mechanisms of action of second generation antipsychotic drugs in schizophrenia: insights from brain imaging studies. Eur Psychiatry 20: 15-27.

Arroyo M, Markou A, Robbins TW, Everitt BJ (1999). Acquisition, maintenance and reinstatement of intravenous cocaine selfadministration under a second-order schedule of reinforcement in rats: effects of conditioned cues and continuous access to cocaine. Psychopharmacology (Berl) 140: 331-344.

Badiani A, Oates MM, Day HE, Watson SJ, Akil H, Robinson TE (1999). Environmental modulation of amphetamine-induced c-fos expression in D1 vs D2 striatal neurons. Behav Brain Res 103: 203-209.

Beaudry G, Langlois MC, Weppe I, Rouillard C, Levesque D (2000). Contrasting patterns and cellular specificity of transcriptional regulation of the nuclear receptor nerve growth factor-inducible B by haloperidol and clozapine in the rat forebrain. J Neurochem 75: 1694-1702.

Beninger RJ, Hoffman DC, Mazurski EJ (1989). Receptor subtypespecific dopaminergic agents and conditioned behavior. Neurosci Biobehav Rev 13: 113-122.

Berretta S, Robertson HA, Graybiel AM (1992). Dopamine and glutamate agonists stimulate neuron-specific expression of Fos-like protein in the striatum. J Neurophysiol 68: 767-777.

Berridge KC, Robinson TE (1998). What is the role of dopamine in reward: hedonic impact, reward learning, or incentive salience? Brain Res Brain Res Rev 28: 309-369.

Cenci MA, Kalen P, Mandel RJ, Wictorin K, Bjorklund A (1992). Dopaminergic transplants normalize amphetamine- and apomorphine-induced Fos expression in the 6-hydroxydopaminelesioned striatum. Neuroscience 46: 943-957.

Chambers RA, Krystal JH, Self DW (2001). A neurobiological basis for substance abuse comorbidity in schizophrenia. Biol Psychiatry 50: 71-83.

Chesi AJ, Feasey-Truger KJ, Alzheimer C, ten Bruggencate G (1995). Dopamine autoreceptor sensitivity is unchanged in rat nucleus accumbens after chronic haloperidol treatment: an in vivo and in vitro voltammetric study. Eur J Neurosci 7: $2450-2457$.

Compton DR, Johnson KM (1989). Effects of acute and chronic clozapine and haloperidol on in vitro release of acetylcholine and dopamine from striatum and nucleus accumbens. J Pharmacol Exp Ther 248: 521-530.

Danna CL, Elmer GI (2010). Disruption of conditioned reward association by typical and atypical antipsychotics. Pharmacol Biochem Behav 96: 40-47.

de Wit H, Stewart J (1981). Reinstatement of cocaine-reinforced responding in the rat. Psychopharmacology (Berl) 75: 134-143.

Ericson H, Radesater AC, Servin E, Magnusson O, Mohringe B (1996). Effects of intermittent and continuous subchronic administration of raclopride on motor activity, dopamine turnover and receptor occupancy in the rat. Pharmacol Toxicol 79: 277-286.

Farde L, Nordstrom AL, Wiesel FA, Pauli S, Halldin C, Sedvall G (1992). Positron emission tomographic analysis of central D1 and D2 dopamine receptor occupancy in patients treated with classical neuroleptics and clozapine. Relation to extrapyramidal side effects. Arch Gen Psychiatry 49: 538-544.

Farde L, Wiesel FA, Nordstrom AL, Sedvall G (1989). D1- and D2dopamine receptor occupancy during treatment with conventional and atypical neuroleptics. Psychopharmacology (Berl) 99(Suppl): S28-S31.

Flagel SB, Watson SJ, Akil H, Robinson TE (2008). Individual differences in the attribution of incentive salience to a rewardrelated cue: influence on cocaine sensitization. Behav Brain Res 186: $48-56$.

Flagel SB, Watson SJ, Robinson TE, Akil H (2007). Individual differences in the propensity to approach signals $v s$ goals promote different adaptations in the dopamine system of rats. Psychopharmacology (Berl) 191: 599-607.

Fletcher PJ (1995). Effects of d-fenfluramine and metergoline on responding for conditioned reward and the response potentiating effect of nucleus accumbens d-amphetamine. Psychopharmacology (Berl) 118: 155-163.

Fukushiro DF, Alvarez Jdo N, Tatsu JA, de Castro JP, Chinen CC, Frussa-Filho R (2007). Haloperidol (but not ziprasidone) withdrawal enhances cocaine-induced locomotor activation and conditioned place preference in mice. Prog Neuropsychopharmacol Biol Psychiatry 31: 867-872.

Fukushiro DF, Carvalho Rde C, Ricardo VP, Alvarez Jdo N, Ribeiro LT, Frussa-Filho R (2008). Haloperidol (but not ziprasidone) withdrawal potentiates sensitization to the hyperlocomotor effect of cocaine in mice. Brain Res Bull 77: 124-128.

Gerfen CR (1992). The neostriatal mosaic: multiple levels of compartmental organization. Trends Neurosci 15: 133-139.

Ginovart N, Wilson AA, Hussey D, Houle S, Kapur S (2009). D2-receptor upregulation is dependent upon temporal course of D2-occupancy: a longitudinal [11C]-raclopride PET study in cats. Neuropsychopharmacology 34: 662-671.

Gregg L, Barrowclough C, Haddock G (2007). Reasons for increased substance use in psychosis. Clin Psychol Rev 27: 494-510.

Halperin R, Guerin Jr JJ, Davis KL (1983). Chronic administration of three neuroleptics: effects of behavioral supersensitivity mediated by two different brain regions in the rat. Life Sci 33: 585-592.

Holden JM, Peoples LL (2010). Effects of acute amphetamine exposure on two kinds of Pavlovian approach behavior. Behav Brain Res 208: 270-273.

Howell LL, Byrd LD (1992). Enhanced sensitivity to the behavioral effects of cocaine after chronic administration of D2-selective dopamine antagonists in the squirrel monkey. J Pharmacol Exp Ther 262: 907-915.

Ichikawa J, Meltzer HY (1992). The effect of chronic atypical antipsychotic drugs and haloperidol on amphetamine-induced dopamine release in vivo. Brain Res 574: 98-104.

Johansson B, Lindstrom K, Fredholm BB (1994). Differences in the regional and cellular localization of $\mathrm{c}$-fos messenger RNA induced by amphetamine, cocaine and caffeine in the rat. Neuroscience 59: 837-849.

Kapur S, VanderSpek SC, Brownlee BA, Nobrega JN (2003). Antipsychotic dosing in preclinical models is often unrepresentative of the clinical condition: a suggested solution based on in vivo occupancy. J Pharmacol Exp Ther 305: 625-631.

Kapur S, Zipursky R, Jones C, Remington G, Houle S (2000). Relationship between dopamine $\mathrm{D}(2)$ occupancy, clinical response, and side effects: a double-blind PET study of firstepisode schizophrenia. Am J Psychiatry 157: 514-520. 
Kavanagh DJ, McGrath J, Saunders JB, Dore G, Clark D (2002). Substance misuse in patients with schizophrenia: epidemiology and management. Drugs 62: 743-755.

Keshavan MS, Tandon R, Boutros NN, Nasrallah HA (2008). Schizophrenia, 'just the facts': what we know in 2008 part 3: neurobiology. Schizophr Res 106: 89-107.

Khantzian EJ (1985). The self-medication hypothesis of addictive disorders: focus on heroin and cocaine dependence. $\mathrm{Am}$ J Psychiatry 142: 1259-1264.

Kosten TA, DeCaprio JL, Nestler EJ (1996). Long-term haloperidol administration enhances and short-term administration attenuates the behavioral effects of cocaine in a place conditioning procedure. Psychopharmacology (Berl) 128: 304-312.

Krystal JH, D'Souza DC, Gallinat J, Driesen N, Abi-Dargham A, Petrakis I et al (2006). The vulnerability to alcohol and substance abuse in individuals diagnosed with schizophrenia. Neurotox Res 10: $235-252$.

Le Moal M, Simon H (1991). Mesocorticolimbic dopaminergic network: functional and regulatory roles. Physiol Rev 71: 155-234.

LeDuc PA, Mittleman G (1993). Interactions between chronic haloperidol treatment and cocaine in rats: an animal model of intermittent cocaine use in neuroleptic treated populations. Psychopharmacology (Berl) 110: 427-436.

LeDuc PA, Mittleman G (1995). Schizophrenia and psychostimulant abuse: a review and re-analysis of clinical evidence. Psychopharmacology (Berl) 121: 407-427.

Levesque D, Rouillard C (2007). Nur77 and retinoid X receptors: crucial factors in dopamine-related neuroadaptation. Trends Neurosci 30: 22-30.

Li M, Fletcher PJ, Kapur S (2007). Time course of the antipsychotic effect and the underlying behavioral mechanisms. Neuropsychopharmacology 32: 263-272.

Mead AN, Crombag HS, Rocha BA (2004). Sensitization of psychomotor stimulation and conditioned reward in mice: differential modulation by contextual learning. Neuropsychopharmacology 29: 249-258.

Natesan S, Reckless GE, Nobrega JN, Fletcher PJ, Kapur S (2006). Dissociation between in vivo occupancy and functional antagonism of dopamine $\mathrm{D}(2)$ receptors: comparing aripiprazole to other antipsychotics in animal models. Neuropsychopharmacology 31: 1854-1863.

O’Brien CP, Childress AR, Ehrman R, Robbins SJ (1998). Conditioning factors in drug abuse: can they explain compulsion? J Psychopharmacol 12: 15-22.

Owen RR, Fischer EP, Booth BM, Cuffel BJ (1996). Medication noncompliance and substance abuse among patients with schizophrenia. Psychiatr Serv 47: 853-858.

Palmiter RD (2008). Dopamine signaling in the dorsal striatum is essential for motivated behaviors: lessons from dopaminedeficient mice. Ann NY Acad Sci 1129: 35-46.

Panlilio LV, Weiss SJ, Schindler CW (1996). Cocaine selfadministration increased by compounding discriminative stimuli. Psychopharmacology (Berl) 125: 202-208.

Parkinson JA, Olmstead MC, Burns LH, Robbins TW, Everitt BJ (1999). Dissociation in effects of lesions of the nucleus accumbens core and shell on appetitive pavlovian approach behavior and the potentiation of conditioned reinforcement and locomotor activity by D-amphetamine. J Neurosci 19: 2401-2411.

Paxinos G, Watson C (1986). The Rat Brain in Stereotaxic Coordinates, 2nd edn. Academic Press: New York.

Pencer A, Addington J (2003). Substance use and cognition in early psychosis. J Psychiatry Neurosci 28: 48-54.

Perkins DO (1999). Adherence to antipsychotic medications. J Clin Psychiatry 60(Suppl 21): 25-30.

Pilowsky LS, Costa DC, Ell PJ, Murray RM, Verhoeff NP, Kerwin RW (1992). Clozapine, single photon emission tomography, and the D2 dopamine receptor blockade hypothesis of schizophrenia. Lancet 340: 199-202.
Potvin S, Pampoulova T, Mancini-Marie A, Lipp O, Bouchard RH, Stip E (2006). Increased extrapyramidal symptoms in patients with schizophrenia and a comorbid substance use disorder. J Neurol Neurosurg Psychiatry 77: 796-798.

Pudiak CM, Bozarth MA (1997). Nitric oxide synthesis inhibition attenuates haloperidol-induced supersensitivity. I Psychiatry Neurosci 22: 61-64.

Rebec GV, Peirson EE, McPherson FA, Brugge K (1982). Differential sensitivity to amphetamine following long-term treatment with clozapine or haloperidol. Psychopharmacology (Berl) 77: 360-366.

Regier DA, Farmer ME, Rae DS, Locke BZ, Keith SJ, Judd LL et al (1990). Comorbidity of mental disorders with alcohol and other drug abuse. Results from the Epidemiologic Catchment Area (ECA) Study. JAMA 264: 2511-2518.

Remington G (2010). Antipsychotic dosing: still a work in progress. Am J Psychiatry 167: 623-625.

Remington G, Seeman P, Feingold A, Mann S, Shammi C, Kapur S (2010). 'Extended' antipsychotic dosing in the maintenance treatment of schizophrenia: a double-blind, placebo-controlled trial. J Clin Psychiatry (e-pub ahead of print).

Remington G, Seeman P, Shammi C, Mann S, Kapur S (2005). 'Extended' antipsychotic dosing: rationale and pilot data. J Clin Psychopharmacol 25: 611-613.

Robbins TW (1978). The acquisition of responding with conditioned reinforcement: effects of pipradrol, methylphenidate, d-amphetamine, and nomifensine. Psychopharmacology (Berl) 58: 79-87.

Robbins TW, Watson BA, Gaskin M, Ennis C (1983). Contrasting interactions of pipradrol, d-amphetamine, cocaine, cocaine analogues, apomorphine and other drugs with conditioned reinforcement. Psychopharmacology (Berl) 80: 113-119.

Roberts DC, Vickers G (1987). The effect of haloperidol on cocaine self-administration is augmented with repeated administrations. Psychopharmacology (Berl) 93: 526-528.

Robertson HA, Paul ML, Moratalla R, Graybiel AM (1991). Expression of the immediate early gene $\mathrm{c}$-fos in basal ganglia: induction by dopaminergic drugs. Can J Neurol Sci 18(3 Suppl): 380-383.

Robinson TE, Flagel SB (2009). Dissociating the predictive and incentive motivational properties of reward-related cues through the study of individual differences. Biol Psychiatry 65: 869-873.

Ruskin DN, Marshall JF (1994). Amphetamine- and cocaineinduced fos in the rat striatum depends on D2 dopamine receptor activation. Synapse 18: 233-240.

Samaha AN, Reckless GE, Seeman P, Diwan M, Nobrega JN, Kapur S (2008). Less is more: antipsychotic efficacy is greater with transient rather than continuous drug delivery. Biol Psychiatry 64: $145-152$.

Samaha AN, Seeman P, Stewart J, Rajabi H, Kapur S (2007). 'Breakthrough' dopamine supersensitivity during ongoing antipsychotic treatment leads to treatment failure over time. J Neurosci 27: 2979-2986.

Schneier FR, Siris SG (1987). A review of psychoactive substance use and abuse in schizophrenia. Patterns of drug choice. J Nerv Ment Dis 175: 641-652.

Schultz W (1998). Predictive reward signal of dopamine neurons. J Neurophysiol 80: 1-27.

See RE, Chapman MA, Murray CE, Aravagiri M (1992). Regional differences in chronic neuroleptic effects on extracellular dopamine activity. Brain Res Bull 29: 473-478.

Shaham Y, Shalev U, Lu L, De Wit H, Stewart J (2003). The reinstatement model of drug relapse: history, methodology and major findings. Psychopharmacology (Berl) 168: 3-20.

Smith RC, Davis JM (1975). Behavioral supersensitivity to apomorphine and amphetamine after chronic high dose haloperidol treatment. Psychopharmacol Commun 1: 285-293. 
Stinus L, Nadaud D, Deminiere JM, Jauregui J, Hand TT, Le Moal M (1989). Chronic flupentixol treatment potentiates the reinforcing properties of systemic heroin administration. Biol Psychiatry 26: 363-371.

Tauscher J, Jones C, Remington G, Zipursky RB, Kapur S (2002). Significant dissociation of brain and plasma kinetics with antipsychotics. Mol Psychiatry 7: 317-321.

Taylor JR, Robbins TW (1984). Enhanced behavioural control by conditioned reinforcers following microinjections of d-amphetamine into the nucleus accumbens. Psychopharmacology (Berl) 84: 405-412.

Tremblay M, Rouillard C, Levesque D (1999). Dopamine D3 receptor antisense administration reduces basal c-fos and NGFI$B$ mRNA levels in the rat forebrain. Synapse 32: 51-57.

Uslaner J, Badiani A, Norton CS, Day HE, Watson SJ, Akil H et al (2001). Amphetamine and cocaine induce different patterns of c-fos mRNA expression in the striatum and subthalamic nucleus depending on environmental context. Eur J Neurosci 13: 1977-1983.

Wadenberg ML, Kapur S, Soliman A, Jones C, Vaccarino F (2000). Dopamine D2 receptor occupancy predicts catalepsy and the suppression of conditioned avoidance response behavior in rats. Psychopharmacology (Berl) 150: 422-429.

Wadenberg ML, Soliman A, VanderSpek SC, Kapur S (2001). Dopamine $\mathrm{D}(2)$ receptor occupancy is a common mechanism underlying animal models of antipsychotics and their clinical effects. Neuropsychopharmacology 25: 633-641.

Wolkin A, Barouche F, Wolf AP, Rotrosen J, Fowler JS, Shiue CY et al (1989). Dopamine blockade and clinical response: evidence for two biological subgroups of schizophrenia. Am J Psychiatry 146: 905-908.

Supplementary Information accompanies the paper on the Neuropsychopharmacology website (http://www.nature.com/npp) 